\title{
Musikinésia: Jogo Eletrônico gratuito para a Aprendizagem de Teclado e Leitura Musical
}

\author{
Rogério A. Bordini, Joice L. Otsuka, Delano M. Beder, Lucas F. Fonseca, Antônio \\ P. A. Nunes, Daniel L. Santiago, Pablo A. G. de Freitas, Glauber L. A. Santiago, \\ Marcia R. G. de Oliveira
}

\author{
Laboratório de Objetos de Aprendizagem (LOA) \\ Universidade Federal de São Carlos (UFSCar), Caixa Postal 676 - CEP: 13565.905 \\ São Carlos/SP - Brasil \\ rogerio.bordini@sead.ufscar.br, \{joice, delano\}@dc.ufscar.br, \\ $\{$ glauber, maroz\}@ufscar.br
}

\begin{abstract}
Resumo. O ensino de música nas escolas de educação básica tem se tornado mais constante nos últimos anos, contudo, ao mesmo tempo tem sido alvo das discussões entre gestores, docentes e pesquisadores devido às dificuldades que são enfrentadas pelos professores no cotidiano escolar para se promover um ensino musical de qualidade. Problemas infraestruturais e carência de instrumentos impedem, muitas vezes, que a educação musical seja promovida de forma efetiva. Ao lado disso, as escolas a cada vez mais sofrem pressão para que suas ações pedagógicas estejam alinhadas com o contexto tecnológico no qual os alunos estão imersos. Esse trabalho, portanto, apresenta o jogo eletrônico educacional Musikinésia, recurso que promove o ensino de teclado musical e leitura de partitura por meio de uma aventura fantástica de um jovem músico. Esse projeto foi desenvolvido com o intuito de oferecer uma solução lúdica, gratuita e educativa a alunos e professores de graduação e educação básica.
\end{abstract}

\section{Cenário de uso}

A promulgação da Lei 11.769 em 2008 instituiu no artigo 26 o ensino de Música como conteúdo curricular obrigatório da educação básica [Brasil 2006], cujas práticas educacionais em música têm crescido significativamente nos últimos anos. Contudo, o ensino de Música em muitas escolas brasileiras tem sido prejudicado pela ausência de espaços apropriados para realização de atividades práticas relacionadas aos conteúdos musicais. A falta de estruturas físicas e a carência de instrumentos implicam em formações lacunares aos alunos, visto que muitos conceitos musicais, para serem efetivamente compreendidos, necessitam ser praticados, ouvidos e tocados.

Ao lado disso, as escolas a cada vez mais sofrem pressão diante da atual demanda pela inovação de suas iniciativas relacionadas ao ensino. $O$ contexto tecnológico para a inserção de tecnologias digitais como forma de aprimorar o ensino e aprendizagem de conteúdos, mostra-se cada vez mais promissor acenando com a possibilidade de tornálos mais condizente à realidade que circunda os alunos. Prensky (2001) destaca as mudanças no estilo cognitivo dos nativos digitais (pessoas que nasceram no fim do século XXI), as quais podem ser consideradas como: processamento de informações em 
uma velocidade mais alta; preferência por gráficos a textos; acesso aleatório e não sequencial; além de os nativos digitais serem extremamente conectados, ativos e fluentes em tecnologias. O autor, ao lado de outros pesquisadores [Gee 2005; Squire 2007], ainda observa a necessidade de se rever as teorias e práticas educacionais para que estejam mais adequadas a esses novos estilos de aprendizagem, e defende que essas práticas sejam baseadas em jogos, justamente por estarem alinhadas com as necessidades e os estilos de aprendizagem da geração atual e futura, por motivar e por ser versátil, podendo ser adaptada a diferentes disciplinas, informações ou habilidades a serem aprendidas.

O jogo educacional Musikinésia, desenvolvido para o ensino de teclado musical e leitura de partituras, portanto, surge como um recurso gratuito e lúdico para auxiliar professores em diversos contextos do ensino, nos quais poderão utilizar o jogo em escolas para promover a alfabetização musical de forma significativa aos alunos.

\section{Desenvolvimento}

O jogo Musikinésia foi desenvolvido pelo Laboratório de Objetos de Aprendizagem $(\text { LOA })^{1}$ da UFSCar durante os anos de 2014 e 2015, cujo projeto surgiu a partir de uma demanda apresentada por um professor do curso de Licenciatura em Música da UFSCar: criar um objeto de aprendizagem capaz de auxiliar os alunos na identificação das notas no teclado musical. Assim, para atender à proposta, a equipe desenvolvedora seguiu os seguintes procedimentos metodológicos:

1. Estudos e pesquisas nas áreas de design de interação [Rogers et. al. 2013] e avaliação de jogos educacionais, realizados por meio de encontros semanais com a participação dos estudantes e docentes do projeto;

2. Pesquisa sobre o conteúdo específico e trabalhos relacionados;

3. Levantamento de demandas de outros professores do Ensino Técnico e de graduação em Música, relacionadas à demanda apresentada inicialmente;

4. Concepção do jogo com base em demandas identificadas (brainstorm; definição inicial de mecânica, narrativa, arte, tecnologia);

5. Criação de um protótipo de alta fidelidade e realização de sessões de testes com diferentes perfis de usuário (no escopo do público-alvo);

6. Ciclos iterativos de testes, análises, refinamentos do design/protótipo.

7. Utilização de métodos tradicionais de avaliação, como observação de uso.

A equipe responsável pelo projeto foi composta por quatro estudantes de graduação (cursos de Música, Ciência da Computação, Engenharia da Computação e Imagem e Som) e um aluno de mestrado em Educação, que atuaram como projetistas, desenvolvedores, ilustradores, músicos e especialistas no conteúdo, além de receber apoio da coordenação de docentes das áreas de Música, Computação e Educação. Todo

\footnotetext{
1 Espaço interdisciplinar de estudos e pesquisas de novas tecnologias e metodologias para o desenvolvimento de objetos de aprendizagem interativos abertos, concentrados na utilização dos games como objetos capazes de proporcionar um aprendizado lúdico ao estudante/jogador. Website: http://www.loa.sead.ufscar.br/
} 
o processo de design e desenvolvimento do jogo é mais bem detalhado em Bordini et. al. (2014a).

Para desenvolvimento do jogo foi utilizado o motor $U_{n i t y}^{2}$, que traz um conjunto de funcionalidades que facilitam e agilizam a criação de games em duas dimensões, permitindo ainda uma maior praticidade quanto à programação (na linguagem $\mathrm{C \#}$ ). $\mathrm{O}$ software utilizado para a produção das músicas foi o Reason ${ }^{3}$, o qual possui um banco de samplers e efeitos que auxiliam na composição das trilhas.

Foram realizados dois processos de avaliação do game. O primeiro ocorreu em 2014, com oito pessoas voluntárias e quatro professores de Música, os quais testaram o game utilizando o mouse e o teclado QWERTY. Com os resultados obtidos nesse primeiro processo, cujos dados foram coletados por meio de questionários online $e^{4} \mathrm{e}$ entrevistas, foi possível realizar ajustes referentes à interface (disposição das informações na tela) e mecânica do jogo. Esse processo é descrito em Bordini et. al. (2014b).

No segundo processo de testes, em 2015, o protótipo foi validado por meio de uma aplicação presencial com alunos e professores de um curso de Licenciatura em Música, com utilização de um teclado MIDI/USB. Assim, os testes ocorreram com dois grupos de alunos da graduação de Licenciatura em Música da UFSCar durante as aulas da disciplina de Teclado I, ministrada por dois professores. Cada turma possuía sete alunos, sendo em sua maioria conhecedores de música com habilidade de leitura de partitura, porém com pouco ou nenhum conhecimento em teclado. Para cada aplicação foram montados três sets com o jogo em uma sala reservada, compostos por um notebook, um teclado com cabo MIDI/USB e fones de ouvido; e cada sessão de testes teve duração média de 40 minutos, sendo 20 para o teste com o jogo e 20 para discussão em grupo. Primeiramente foi realizada uma breve apresentação do jogo aos alunos, sem aprofundamento de detalhes, pois se pretendia analisar o quanto o game seria capaz de apresentar seus objetivos e conteúdos de forma autocontida [Silveira e Carneiro 2012]. Ao final de processo, o gerente de testes (papel que foi desempenhado por um dos designers do Musikinésia) realizou discussões acerca das impressões do jogo, fazendo questões referentes à jogabilidade básica, clareza dos objetivos educacionais e o quanto foi capaz de ensinar/aprimorar o conhecimento musical. Os dados coletados foram registrados por meio de anotações e posteriormente repassados à equipe para análise coletiva.

\section{Apresentação do Software}

Musikinésia ${ }^{5}$, trata-se de um jogo educacional aberto 2D desenvolvido para PC e tablets, capaz de promover a identificação das teclas de um teclado musical associando-as a uma

\footnotetext{
${ }^{2}$ http://unity3d.com/

3 http://www.propellerheads.se/products/reason/

4 Para realização das perguntas do questionário, foi tomado como base o método EGameFlow [Fu et. al., 2009], uma escala avaliativa para analisar aspectos específicos do jogo, como jogabilidade, clareza de objetivos, desafio, interface, imersão e aprendizagem.

$\mathrm{O}$ jogo pode ser gratuitamente acessado no seguinte endereço: http://www.loa.sead.ufscar.br/musikinesia.php. O vídeo demonstrativo pode ser visualizado no seguinte link: https://youtu.be/pHq7Up7yhvM. O jogo também possui um trailer no seguinte endereço: https://youtu.be/LOesmxQGOnU.
} 
V Congresso Brasileiro de Informática na Educação (CBIE 2016)

Anais dos Workshops do V Congresso Brasileiro de Informática na Educação (CBIE 2016)

partitura, além de ensinar outros conceitos musicais básicos, como andamentos, acidentes e leitura de pentagrama.

\subsection{Narrativa}

O jogo traz a bem humorada narrativa de Tom (Fig. 1), um jovem garoto que acidentalmente encontra um teclado musical dotado de um poder especial chamado musikinésis. No entanto, leigo em música, o protagonista decide aprender o instrumento para descobrir seus dotes mágicos e, para isso, embarca numa aventura por três mundos diferentes (Subúrbio, Máfia e Pirata) para adquirir novos conhecimentos musicais.

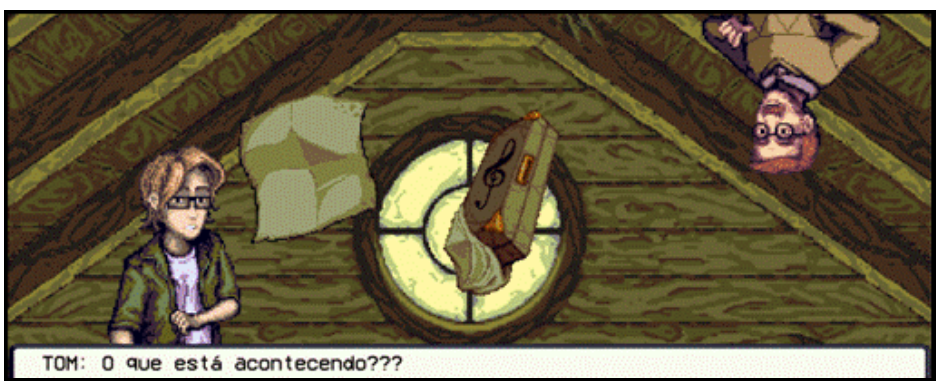

Figura 1. Cena de Diálogo entre Tom e seu pai

\subsection{Mecânica}

A mecânica baseia-se no ato de tocar as notas de uma linha melódica utilizando o teclado musical, pressionando as teclas correspondentes com o mouse, com o teclado QWERTY (teclado normal dos computadores) ou com um teclado MIDI/USB. Essas notas atravessam a tela da direita para a esquerda e o jogador deve tocá-las no momento em que entrarem numa região delimitada na partitura, onde é preciso pressionar as teclas correspondentes às respectivas notas (Fig. 2). Caso o jogador cometa uma quantidade grande de erros, seu medidor de desempenho diminuirá e ele precisará recomeçar a música.

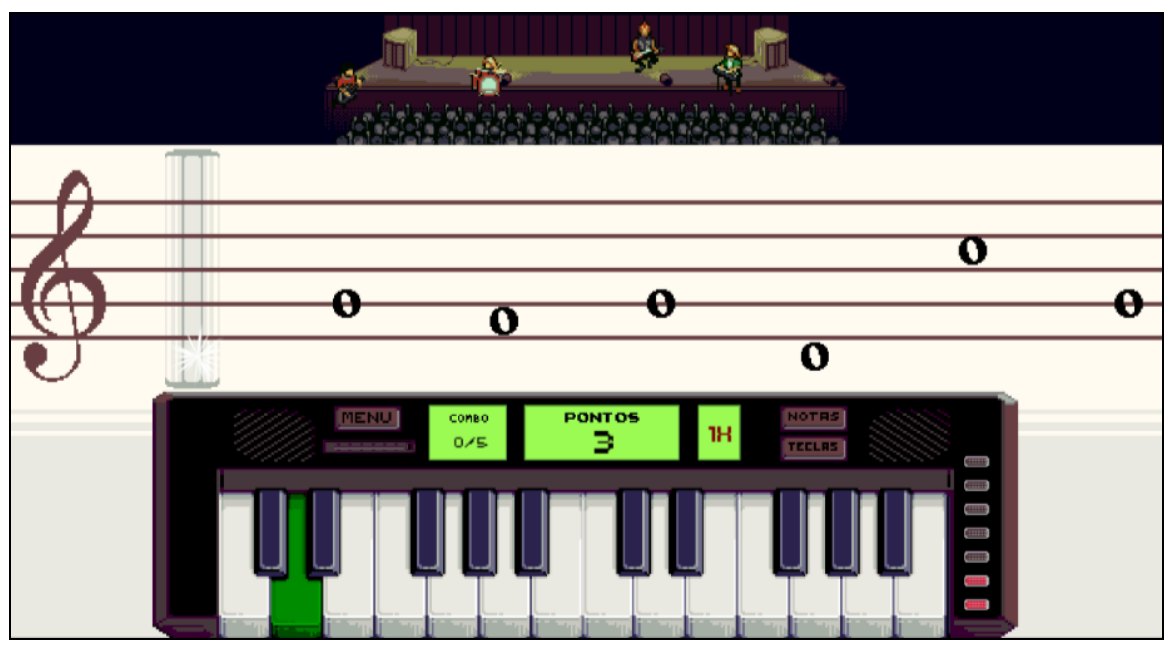

Figura 2. Demonstração de gameplay de Musikinésia

As fases foram projetadas para terem dificuldade gradativa, com a execução de músicas mais simples no início até as de nível mais elevado ao final. Existem dois modos jogáveis: Modo Campanha, o qual se trata do modo principal em que o jogador 
V Congresso Brasileiro de Informática na Educação (CBIE 2016)

Anais dos Workshops do V Congresso Brasileiro de Informática na Educação (CBIE 2016)

progride por onze fases de nível gradativo de dificuldade, acompanhado de tutoriais explicando os conceitos básicos de identificação das notas no teclado e outros elementos musicais; e o Modo Treino, no qual o jogador poderá praticar as músicas para se aperfeiçoar. Além disso, o jogo possui um Sistema de Pontuação que funciona como um importante elemento do jogo que indica a qualidade do desempenho do jogador. Esse sistema encontra-se no corpo do teclado (Fig. 3) e é composto por: Medidor de Desempenho, o qual delimita a quantidade de erros que o jogador pode cometer na música; Pontos, o qual demonstra o quanto o jogador contabiliza a cada acerto; Combo, o qual registra o número de acertos realizados sequencialmente; e, por fim, o Multiplicador de Pontos, que funciona como um multiplicador dos pontos que o jogador realiza seguidamente.

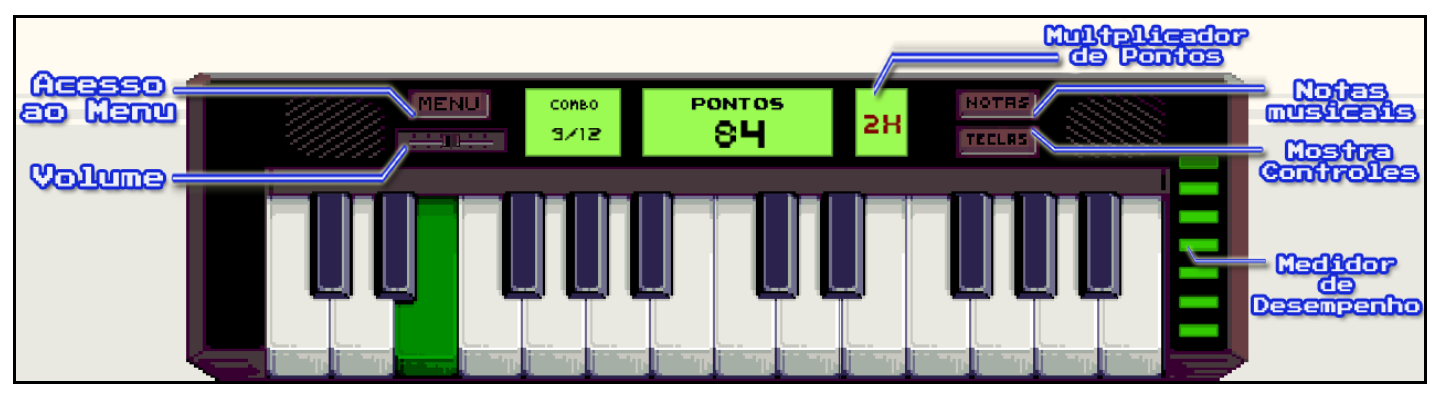

Figura 3. Funcionalidades da Interface e Sistema de Pontuação

\subsection{Estética}

Como visto nas Figuras 1, 2 e 3, o jogo possui um visual 2D, com gráficos desenhados seguindo o estilo Pixel Art (arte pixelizada). Esse estilo de visual foi escolhido por ser de leve processamento e condizente ao tom cômico da narrativa do game.

Todas as músicas do jogo receberam especial atenção durante seu processo de design. Dois estudantes e um professor de Música elaboraram um esquema de aprendizagem com base na compreensão de como o jogador/estudante aprende a ler uma partitura junto com o teclado. Assim, as músicas foram produzidas seguindo um plano de composição no qual constava a indicação das notas que deveriam ser utilizados para cada fase e o estilo musical consonante a cada mundo da aventura.

\subsection{Matriz de Aprendizagem}

Paralelamente à aprendizagem de teclas do teclado musical, o jogo visa favorecer a aprendizagem de outras habilidades musicais. Na tabela abaixo é exemplificado como esses conceitos musicais são trabalhados paralelamente à narrativa, dividido pelas fases do game:

Tabela 1. Matriz de Aprendizagem separada por conjunto de fases

\begin{tabular}{|c|c|c|}
\hline FASE & CONCEITO/HABILIDADE & NARRATIVA \\
\hline Subúrbio & $\begin{array}{c}\text { Introdução às noções básicas de } \\
\text { leitura musical (pentagrama e clave } \\
\text { de sol) e identificação das notas no } \\
\text { teclado musical }\end{array}$ & $\begin{array}{c}\text { O pai de Tom ensina os conceitos } \\
\text { básicos do instrumento e de teoria na } \\
1^{\text {a }} \text { fase (tutorial) }\end{array}$ \\
\hline Máfia & Andamento (velocidade da música). & O chefe Dom Macarrone desafia Tom \\
\hline
\end{tabular}


V Congresso Brasileiro de Informática na Educação (CBIE 2016)

Anais dos Workshops do V Congresso Brasileiro de Informática na Educação (CBIE 2016)

\begin{tabular}{|c|c|c|}
\hline Ex: allegro, moderato, presto & $\begin{array}{c}\text { a tocar músicas com alteração da } \\
\text { velocidade }\end{array}$ \\
\hline Pirata & Acréscimo de Sustenidos e Bemóis & $\begin{array}{c}\text { Tom precisa ajudar o Pirata Morgan a } \\
\text { capturar outro pirata e aprende a } \\
\text { causar "acidentes" usando a } \\
\text { musikinésis }\end{array}$ \\
\hline
\end{tabular}

Além disso, o jogo possui quebra-cabeças musicais (puzzles) durante o Modo Campanha que se baseiam em três situações diferentes de resolução de problemas. Por exemplo, o primeiro deles baseia-se em um desafio em que Tom precisa pressionar teclas específicas no teclado (Dó - Fá e Mi - Si) para mover uma pintura torta na parede e levála até um local demarcado (Fig. 4). Este quebra-cabeça foi projetado para facilitar o entendimento do jogador acerca da localização de teclas no teclado, por meio da identificação de teclas com formatos semelhantes.

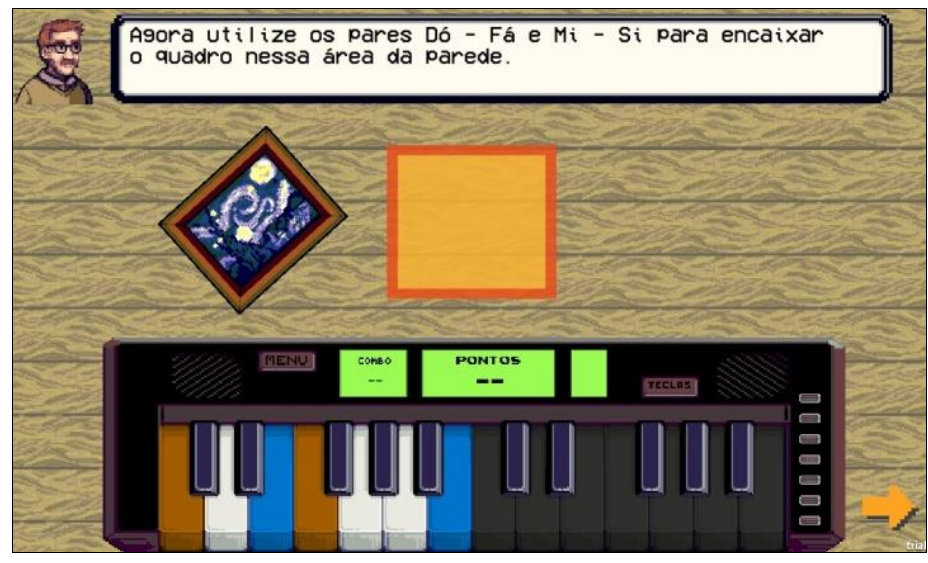

Figura 4. Exemplo de Quebra-Cabeça

\subsection{Jogando com teclado MIDI/USB}

Musikinésia permite a integração de um teclado MIDI/USB que pode ser usado como controle para a execução das músicas. Esta opção pode ser um recurso útil aos professores que queiram usar o jogo para aprimorar o processo de aprendizagem de teclado musical do aluno, pois, além de ser um fator motivacional devido ao aspecto lúdico do game, a utilização de um teclado MIDI/USB permite que o aluno tenha uma experiência natural ao jogar, aproximando-o da real prática de tocar um teclado. 
V Congresso Brasileiro de Informática na Educação (CBIE 2016)

Anais dos Workshops do V Congresso Brasileiro de Informática na Educação (CBIE 2016)

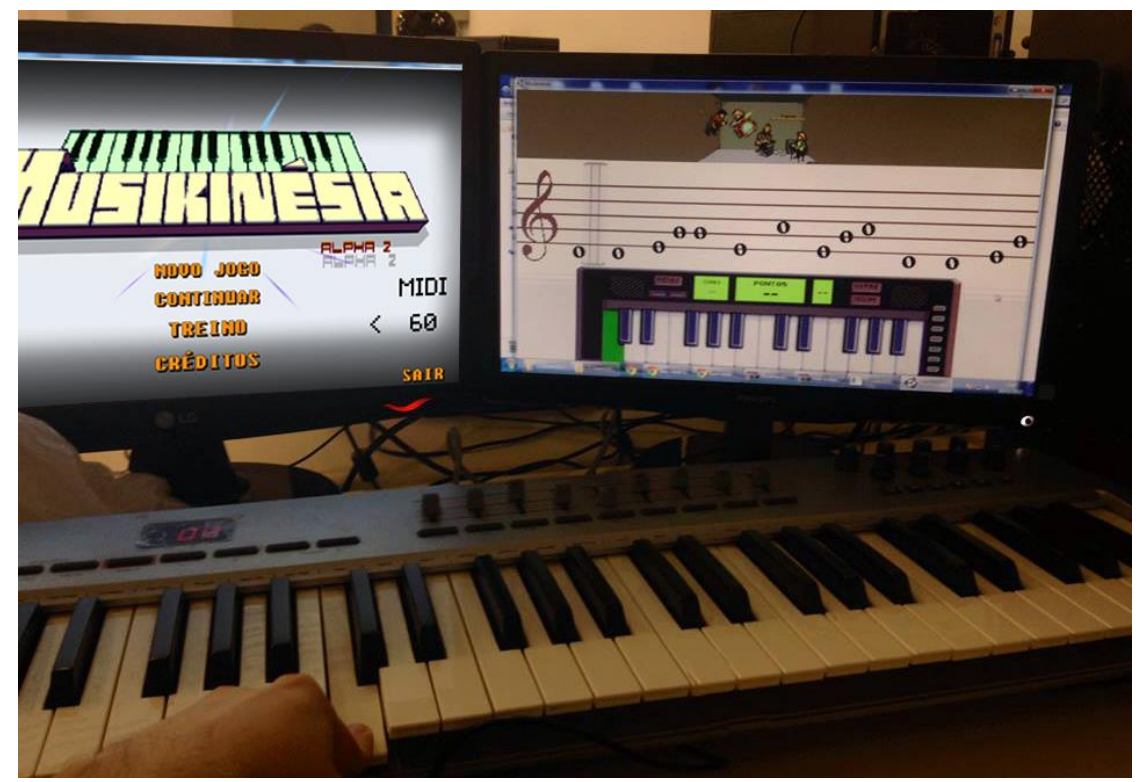

Figura 5. Demonstração de interação do jogo pelo Teclado MIDI/USB

\section{Considerações finais}

Os feedbacks obtidos tanto por meio dos testes com os alunos, quanto pela observação dos professores, de forma geral, apontaram que Musikinésia conseguiu atender os objetivos de ensino das teclas de teclado e de outros conceitos musicais. Por outro lado, foi possível observar que alguns alunos se sentiram confusos em relação ao posicionamento correto das mãos sobre o teclado e tiveram dificuldades em vencer algumas fases. Esses feedbacks indicaram a necessidade de balanceamento da dificuldade do jogo e inserção de informações sobre a posição correta das mãos no teclado em músicas específicas do game.

Como trabalhos futuros pretende-se implementar uma opção de inserção de músicas pelo próprio professor. O LOA vem pesquisando e trabalhando em uma aplicação que permitirá a criação de melodias por meio da importação de arquivos $\mathrm{MIDI}^{6}$ no sistema do jogo, o qual automaticamente irá gerar as notas escritas para serem tocadas por meio de sua mecânica. Essa função dará autonomia para que o professor crie seus próprios conteúdos musicais e os compartilhe com os alunos, ampliando as possibilidades de trabalhar melodias e outros conceitos musicais.

Ademais, por Musikinésia ser um recurso educacional aberto, seus componentes ficarão disponíveis para a comunidade no Repositório Digital Livre Saber ${ }^{7}$, repositório digital de acesso livre da SEaD/UFSCar, onde está sendo organizado um acervo de objetos educacionais multimídia produzidos como recursos educacionais abertos.

Também almeja-se levar o jogo a instituições públicas de ensino e, juntamente com professores de Música, realizar aplicações práticas do jogo com alunos da educação

\footnotetext{
${ }^{6}$ Inventado em 1983, MIDI (Musical Instrument Digital Interface) é um protocolo de comunicação que permite instrumentos digitais interagirem entre si e com computadores. Um arquivo MIDI não contém sons, apenas instruções descrevendo as notas tocadas em uma performance e as informações sobre elas [Hansen s/a].

${ }^{7}$ http://livresaber.sead.ufscar.br
} 
V Congresso Brasileiro de Informática na Educação (CBIE 2016)

Anais dos Workshops do V Congresso Brasileiro de Informática na Educação (CBIE 2016)

básica a fim de verificar se o referido jogo se apresenta como uma tecnologia digital capaz de promover benefícios educacionais de forma lúdica e significativa.

\section{Referências}

Bordini, R. A., Otsuka, J. L., Beder, D. M., Fonseca, L. L., Freitas, P. G., Nunes, A. P., Santiago, D. L. Santiago, G. L. e Oliveira, M. R. (2014a). Processo de Design de um Jogo Eletrônico Para o Aprendizado de Teclado Musical. In XIII Simpósio Brasileiro de Jogos e Entretenimento Digital. SBGames 2014. Porto Alegre/RS.

(2014b). Avaliação do Protótipo de um Game Educacional de Música. In XIX Conferência Internacional sobre Informática na Educação. TISE 2014. Fortaleza/CE.

Brasil. "Diretrizes Curriculares Nacionais do Curso de Graduação em Pedagogia/ Conselho Nacional de Educação". Conselho Pleno. Brasília, 15 de maio de 2006.

Fu, F. L., Su, R. C., e Yu, S. C. (2009) EGameFlow: A Scale to Measure Learners' Enjoyment of E-Learning Games. In Computers \& Education. Elsevier Educational Research Programme.

Gee, J. P. (2005) “Good video games and good learning”. Phi Kappa Phi Forum, n 2.

Hansen, B. (s/a) "Musical Instrument Digital Interface". Disponível em $<$ http://www.hansenb.pdx.edu/pdf/MIDI.pdf $>$ acesso em 26/06/2016.

Prensky, M. "Aprendizagem baseada em jogos digitais". São Paulo: Editora Senac São Paulo, 2001.

Rogers, Y., Sharp, H. e Preece, J. (2013). "Design de Interação: Além da Interação Humano-Computador. 3. Ed. Porto Alegre, Brasil: Bookman.

Silveira, M. S. e Carneiro, M. L. (2012) Diretrizes para a Avaliação da Usabilidade de Objetos de Aprendizagem. In Anais do $23^{\circ}$ Simpósio Brasileiro de Informática na Educação (SBIE 2012). Rio de Janeiro, p. 26-30.

Squire, K. D. (2007) Games, Learning and Society: Building a Field. In Educational Technology. p. 51- 54. 